\title{
Assessment of consumer acceptability and market potential of convenience foods developed from buckwheat (Fagopyrum esculentum)
}

\author{
MANI MISHRA AND SHASHI JAIN
}

Received: 20.11.2013; Accepted: 03.11.2014

See end of the paper for authors' affiliations

\section{MANI MISHRA}

Department of Foods and

Nutrition, College of Home

Science, Maharana Pratap

University of Agriculture and

Technology, UDAIPUR

(RAJASTHAN) INDIA

Email: maanvi29@gmail.com
ABSTRACT : Common buckwheat (Fagopyrum esculentum) is a broad-leafed herbaceous annual. It belongs to the family Polygonaceae, which is generally referred to as the buckwheat (Soral-Emietana, 1987). Buckwheat has gained an excellent reputation for its nutritious qualities in the human diet. Its renewed popularity stems from its many bioactive components, which have been shown to provide various health benefits much sought after in natural foods (Eggum and Kreft et al., 1981). Convenience foods are a class of foods which impart convenience to the consumers by way of little or no requirements of major processing or cooking before their consumption. In the present study, consumer acceptability and market potential of convenience foods were assessed. Biscuit, Namkeen, Papad, Pasta, Idli mix were prepared through incorporation of buckwheat whole flour. Consumer acceptability and market potential were assessed through interview schedule. It was found that ready to eat foods as Biscuit and Namkeen were preferred more by consumers and shopkeepers as compared to ready to cook food and Idli mix.

KEY WORDS: Convenience foods, Ready to eat, Assessment

- HOW TO CITE THIS PAPER : Mishra, Mani and Jain, Shashi (2014). Assessment of consumer acceptability and market potential of convenience foods developed from buckwheat (Fagopyrum esculentum). Asian J. Home Sci., 9 (2) : $584-586$. 